\title{
Preface: ASME ISPS 2020
}

\author{
Paul C.-P. Chao' ${ }^{1}$ Yuan $\mathrm{Ma}^{2} \cdot$ Wanchin $\mathrm{Kim}^{3}$
}

Published online: 10 May 2021

(C) The Author(s), under exclusive licence to Springer-Verlag GmbH Germany, part of Springer Nature 2021

\section{The 29th ASME annual conference on information storage and processing systems, San Francisco, California, USA}

The 29th ASME annual conference on information and storage and processing systems (ASME ISPS 2020), sponsored by ISPS Division, was held at Western Digital Campus in Milpitas, California, USA on June 25-26, 2020. ASME ISPS 2020 offers an ideal forum for researchers in both academic and industrial environments to foster synergies in multidisciplinary areas of the data storage and processing industry, and related areas. Papers presented in this conference addressed technologies and knowledge advancement related to:

- Tribology, dynamics and servo control of nano-micro systems.

- Packaging technologies for solid-state flash storage and memory.

- Fundamentals on energy assisted magnetic recording.

- Data storage solution and system for data center operation and optimization.

- Emerging and future data storage technologies.

- Dynamics and control for future technologies.

- Smart materials.

- Smart sensors and actuators.

- Micro/Nano and biomedical mechatronic systems.

Paul C.-P. Chao

pchao@mail.nctu.edu.tw

Yuan Ma

yuan.ma@tamu.edu

Wanchin Kim

wckim97@ hanbat.ac.kr

1 Department of Electrical and Computer Engineering, National Chiao Tung University, Hsinchu, Taiwan

2 Texas A\&M University, College Station, TX 77843, USA

3 Department of Smart Manufacturing Applied Engineering, Hanbat National University, Daejeon, South Korea
- Optical imaging devices and opto-mechatronic systems.

- Flexible media handling machines and printed electronics, exposing and printing technologies.

- Advanced simulation in science and engineering.

- Application of data and artificial intelligence in mechanical engineering.

The conference featured two keynote speeches and one distinguished talk. The first keynote speech was given by Dr. Siva Sivaram, President, Technology and Strategy, Western Digital. On the second day of the conference, the second keynote was provided by Dr. Bernhard Knigge, Director of the RSS HDI Firmware teams. The distinguished talk was delivered by Dr. John Morris, Ph.D., Chief Technology Officer, Seagate.

ASME ISPE 2020 inherited long tradition to attract annually high-quality contributions from countries around the world. Significant number of papers presented in the conference were research and development results of industry-university research collaborations. In addition to a best conference paper award, starting from 2008 and sponsored by ASME ISPS Division, in ASME ISPS 2020, best track paper awards for outstanding papers in each technical track were presented to outstanding papers. To encourage student participation in the conference as well as to promote student research in information storage and processing systems, ASME ISPS 2020 provided three ISPS Division graduate student fellowships and six ISPS Division graduate student conference scholarships to waive graduate student's conference registration fees.

For archival issue of the ASME ISPS 2020, selected authors of conference papers were invited and encouraged to submit full papers for this special issue. All submitted papers went through a rigorous peer-review process. Most reviewers were world leading experts in relevant fields. Many papers went through substantial revisions before acceptance from reviewers for final publication. Twentyfour papers were selected for publication. Guest editors sincerely thank reviewers who reviewed the manuscripts in a thorough and constructive manner. Without the fast 
responses from all reviewers, this special issue will not have been in production on time.

Prof. Bharat Bhushan, Co-Editor-in-Chief of the Microsystem Technologies facilitated the publication of the special issue in the archival journal and has done so for the past two decades. Special issues have provided a forum for archival publication, which is widely read by the academia and industry practitioners and researchers. Guest editors would like to acknowledge the help from the ASME staff for the ASME ISPS 2020 conference. Furthermore, they would like to thank all session organizers, session (co-) chairs and the ISPS executive members. Last, but not least, a final word of gratitude goes to all presenters and participants of the conference. The ASME ISPS 2020 would not have been successful without their dedicated participation.
Guest Editors:

Distinguished Prof. Paul C.-P. Chao

Department of Electrical and Computer Engineering, National Chiao Tung University, Hsinchu, Taiwan

e-mail: pchao@mail.nctu.edu.tw

Prof. Yuan Ma

Texas A\&M University

College Station, Texas 77843, USA

e-mail: yuan.ma@tamu.edu

Prof. Wanchin Kim

Department of Smart Manufacturing Applied Engineering Hanbat National University

Daejeon, South Korea

e-mail: wckim97@hanbat.ac.kr

Publisher's Note Springer Nature remains neutral with regard to jurisdictional claims in published maps and institutional affiliations. 